\section{Tricuspid regurgitant velocity elevation in a three-year old child with sickle cell anemia and recurrent acute chest syndromes reversed not by hydroxyurea but by bone marrow transplantation}

\author{
Raffaella Colombatti, ${ }^{1}$ Elena Varotto, ${ }^{2}$ \\ Silvia Ricato, ${ }^{2}$ Daniel Nardo, ${ }^{1}$ \\ Nicola Maschietto, ${ }^{2}$ Simone Teso, ${ }^{3}$ \\ Marta Pillon, ${ }^{4}$ Chiara Messina, ${ }^{4}$ \\ Ornella Milanesi, ${ }^{2}$ Laura Sainati $^{1}$ \\ ${ }^{1}$ Clinic of Pediatric Hematology Oncology, \\ Department of Pediatrics, Azienda \\ Ospedaliera-University of Padova, \\ Padova; ${ }^{2}$ Cardiology Unit, Department \\ of Pediatrics, Azienda Ospedaliera- \\ University of Padova, Padova; \\ ${ }^{3}$ University of Padova, Padova; \\ ${ }^{4}$ Bone Marrow Transplant Unit, Clinic of \\ Pediatric Hematology Oncology, \\ Department of Pediatrics, Azienda \\ Ospedaliera-University of Padova, \\ Padova, Italy
}

\section{Abstract}

Elevated Tricuspid Regurgitant Velocity (TRV) has been related to higher mortality in adults and to hemolysis, lower oxygen saturation during 6-minute walk test and acute chest syndrome (ACS) in children with sickle cell disease (SCD). Hydroxyurea (HU) has reduced TRV value in children and adults. We describe a three year old HbSS child with recurrent ACS, hypoperfusion of the left lung, mild hemolysis and persistent TRV elevation. TRV did not normalize after HU, despite improvement in clinical conditions and in baseline laboratory parameters related to hemolysis and blood viscosity, but normalized after bone marrow transplantation (BMT). Our experience suggests that in young patients, TRV reduction can be a positive concomitant effect of BMT.

\section{Introduction}

Tricuspid Regurgitant Velocity (TRV) has become a reliable marker to screen for dopplerdefined pulmonary hypertension ( $\mathrm{PH})$ in sickle cell disease (SCD). ${ }^{1}$ Elevated TRV has been related to higher mortality in adults ${ }^{2}$ and to hemolysis, lower oxygen saturation during 6minute walk test ${ }^{3}$ and acute chest syndrome
$(\mathrm{ACS})^{4}$ in children, even though it's clinical relevance, especially in the paediatric age, is not yet clearly defined. It remains to be determined whether TRV, and its association with mortality, reflects true $\mathrm{PH}$ or is a biomarker of disease severity and systemic vasculopathy in SCD. ${ }^{5}$ In fact, even if TRV measurement on echocardiography can be a first tool to screen for $\mathrm{PH}$ in patients with SCD, recent studies have clearly shown that only a limited number of patients with TRV elevation have $\mathrm{PH}$ as confirmed on cardiac catheterization ${ }^{6}$ and that different factors could play a role in leading to TRV elevation in different subsets of patients. ${ }^{7-8}$ Moreover, the causes involved in the genesis of elevated TRV (role of hemolysis and vasoocclusive thromboembolic factors) and of $\mathrm{PH}$ in SCD are still under investigation.,9-10

Clinical management of TRV elevation is also not clear even if Hydroxyurea (HU) has been demonstrated to lower TRV value in children and adults. ${ }^{11-12}$ The effect of bone marrow transplantation (BMT) on TRV value and Doppler-defined PH in SCD has not yet been reported. We describe a three year old HbSS child with recurrent ACS -resulting in lung hypoperfusion-, mild hemolysis and TRV elevation since age two. He did not improve after HU treatment but 1 year after undergoing BMT from an HbAA HLA-related sibling, presents no signs of hemolysis and normal TRV, although lung damage remained.

\section{Case Report}

A 21-months Nigerian male was diagnosed with $\mathrm{HbSS}$ in occasion of the first ACS presenting with infiltration in the left lung and pleural effusion. At 23 and 26 months he experienced a second and third ACS with infiltration of the left lobe. Steady state hematological parameters are shown in Table 1, while steady state Blood Pressure (BP) and Sat02 were above the $90^{\text {th }}$ percentile and $97-98 \%$, respectively. Steady state TRV at 28 months was $2.8 \mathrm{~m} / \mathrm{sec}$.

At 30 months he began $\mathrm{HU} 10 \mathrm{mg} / \mathrm{kg}$, gradually increased to $30 \mathrm{mg} / \mathrm{kg}$ in four months. The treatment was well tolerated.

At 42 months, 1 year after starting $\mathrm{HU}$, despite improvement of hematological parameters, TRV was still $2.82 \mathrm{~m} / \mathrm{sec}$. BP had dropped to normal values. ECG and cardiac ultrasound (including Tissue Doppler) at 21, 38 and 43 months were normal. He never presented with obstructive sleep apnea or asthma. Transcranial Doppler (TCD) velocities remained conditional before $\mathrm{HU}$ and after $\mathrm{HU}$ -time averaged mean velocity of maximum blood flow (TAMM) of $185 \mathrm{~cm} / \mathrm{sec}$ and 189 $\mathrm{cm} / \mathrm{sec}$, respectively.

Having experienced recurrent ACS and per-
Correspondence: Raffaella Colombatti, MD, PhD, Clinic of Pediatric Haematology-Oncology, Department of Pediatrics, Azienda OspedalieraUniversity of Padova, Via Giustiniani 2, 35100 Padova, Italy.

Tel. $+39.049 .8218006-+39.049 .8213579$.

Fax: +39.049 .8213550 .

E-mail: rcolombatti@gmail.com

Key words: sickle-cell disease, pulmonary hypertension, tricuspid regurgitant jet velocity, hydroxyurea, bone marrow transplantation.

Acknowledgements: the research was performed with grant 07/04 from the Fondazione Citta` della Speranza.

Contributions: $\mathrm{RC}$ had clinical care of the patient, analysed the data and wrote the manuscript; EV, SR, DN, NM, MP had clinical care of the patient and analysed the data; ST analysed the data; OM and $L S$ revised the manuscript

Conflict of interest: the authors report no conflicts of interest.

Received for publication: 26 May 2011.

Revision received: 7 August 2011.

Accepted for publication: 8 August 2011.

This work is licensed under a Creative Commons Attribution NonCommercial 3.0 License (CC BYNC 3.0).

CC Copyright R. Colombatti et al., 2011

Licensee PAGEPress, Italy

Hematology Reports 2011; 3:e12

doi:10.4081/hr.2011.e12

sistent high conditional velocities on TCD, due to availability of an HbAA HLA- matched sibling he was offered BMT.

As part of the BMT work-up he underwent lung CT scan showing numerous perihilar strie dense in the lower left lobe, with increased density of the parenchyma, interpreted as lung scars due to the recurrent ACS, and pulmonary perfusion scintigraphy revealing hypoperfusion of the entire left lung, mainly of the left lower lobe respectively (Figure 1).

At 47 months he received BMT with the following conditioning regimen: Thiotepa 8 $\mathrm{mg} / \mathrm{kg} /$ day (70 mg x2 times on day -7), Treosulfan $14 \mathrm{~g} / \mathrm{m}^{2} /$ day ( 9.8 gr on day $-6,-5$ and -4 ), Fludarabine $40 \mathrm{mg} / \mathrm{m}^{2} /$ day ( $28 \mathrm{mg}$ on day $6,-5,-4$ e -3), antithymocyte globulin 175 $\mathrm{mg} /$ day (on day $-4,-3$ and -2). Polymorphonucleated leukocytes and platelet engraftment occurred at day +20 and +22 respectively. No transplant related complications were observed.

One year after BMT he presents with 100\% chimerism, no $\mathrm{HbS}$ on electrophoresis and is currently well, having experienced no SCDrelated complications. Hematological and bio- 
chemical values are within normal range for age (Table 1) and TRV dropped to $2.01 \mathrm{~m} / \mathrm{sec}$. A pulmonary perfusion scintigraphy performed 1 year after BMT still shows persistence of hypoperfusion of the left lung (unchanged from pre-BMT perfusion scintigraphy).

\section{Discussion}

Our case represents, to our knowledge, the first reported case of a very young SCD child with TRV elevation that did not reduce after HU treatment, but normalized after BMT.

Several factors contribute to the increase in TRV in SCD children, including increased pulmonary flow volume (cardiac output), increased left ventricular filling pressures, increased blood viscosity, and increased pulmonary vascular resistance. ${ }^{8}$ SCD children can also experience systemic hypertension, leftsided volume overload, and abnormal diastolic function, all of which lead to elevated left ventricular filling pressures and secondary elevation of pulmonary artery pressures. Our patient had surely several of the above mentioned factors.

The lack of response of TRV values to $\mathrm{HU}$ has been described in only one older patient with severe $\mathrm{PH}^{11}$ and $\mathrm{HU}$ efficacy in reducing TRV values is still open. In fact, while some studies demonstrated the protective effect of $\mathrm{HU}$ on the development of $\mathrm{PH}$ in adults ${ }^{12}$ and children, ${ }^{11}$ others have not and HU-induced high haemoglobin F levels have, on the contrary, been related to higher TRV velocities. ${ }^{13}$ HU has reversed Doppler-defined PH in SCD children $^{11}$ and adults ${ }^{12}$ probably due to the combined reduction of hemolysis and red cell adhesion, and to the improvement of vascular function, ${ }^{14}$ even when the increase in haemoglobin concentration was modest (from 8.3 to $8.7 \mathrm{~g} / \mathrm{dL}$ and from 7.52 to $7.98 \mathrm{~g} / \mathrm{dL}$ ). ${ }^{11,12}$ But HU was not effective in reducing TRV in our patient, despite the increase in $\mathrm{Hb}$ level (from 7.08 to $8.1 \mathrm{~g} / \mathrm{dL}$ ), the significant increase of $\mathrm{HbF} \%$ and the reduction of hematologic parameters related to hemolysis (reticulocytes, AST) and to blood viscosity (platelets, white blood cells). Additive effect during $\mathrm{HU}$ treatment was normalization of the BP to the 50th percentile, while TCD velocities remained conditional (TAMM of $185 \mathrm{~cm} / \mathrm{sec}, 189 \mathrm{~cm} / \mathrm{sec}$ and 105 $\mathrm{cm} / \mathrm{sec}$ before $\mathrm{HU}$, after $\mathrm{HU}$ and after BMT respectively).

One year after BMT, all haematological parameters and TRV gradually returned to normal values $(2.7,2.5,2 \mathrm{~m} / \mathrm{sec}$ at 3,8 and 12 months after BMT) while pulmonary scintigraphy remained impaired, suggesting a non causative role of in situ thrombosis in generating high TRV in our patient. In fact, in situ

Table 1. Laboratory values before $\mathrm{HU}$ treatment, after 1 year of $\mathrm{HU}$ treatment and 1 year after bone marrow transplantation.

\begin{tabular}{lcccr} 
Variable & $\begin{array}{c}\text { Before HU } \\
\text { Mean } \pm \text { SD }\end{array}$ & $\begin{array}{c}\text { 1 year After HU } \\
\text { Mean } \pm \text { SD }\end{array}$ & $\begin{array}{c}\text { 1 year After BMT } \\
\text { Mean } \pm \text { SD }\end{array}$ & P \\
Aspartate aminotransferase (U/L) & $80.67 \pm 21.03$ & $53.88 \pm 7.02$ & $57.25 \pm 13.52$ & 0.021 \\
Indirect bilirubin $(\mathrm{mcmol} / \mathrm{L})$ & $49.95 \pm 7.28$ & $25.67 \pm 2.65$ & $5.10 \pm 1.41$ & 0.000 \\
\hline White Blood Cells $\left(\times 10^{9} / \mathrm{L}\right)$ & $15840 \pm 4343.15$ & $9704.17 \pm 2245.44$ & $4745.83 \pm 1739.31$ & 0.000 \\
Hemoglobin $(\mathrm{g} / \mathrm{dL})$ & $7.08 \pm 0.46$ & $8.10 \pm 0.49$ & $12.29 \pm 0.64$ & 0.000 \\
\hline Hb F $(\%)$ & $5.10 \pm 0.62$ & $17.31 \pm 1.96$ & $2.15 \pm 2.76$ & 0.000 \\
Platelets $\left(\mathrm{x} 10^{9} / \mathrm{L}\right)$ & $550600 \pm 228802.97$ & $393769.23 \pm 170706.94$ & $270090.91 \pm 34725.94$ & 0.006 \\
\hline Reticulocytes $\left(\mathrm{x} 10^{9} / \mathrm{L}\right)$ & $422500 \pm 32809.75$ & $345016.67 \pm 113780.79$ & $18300 \pm 10137.06$ & 0.001 \\
\hline
\end{tabular}
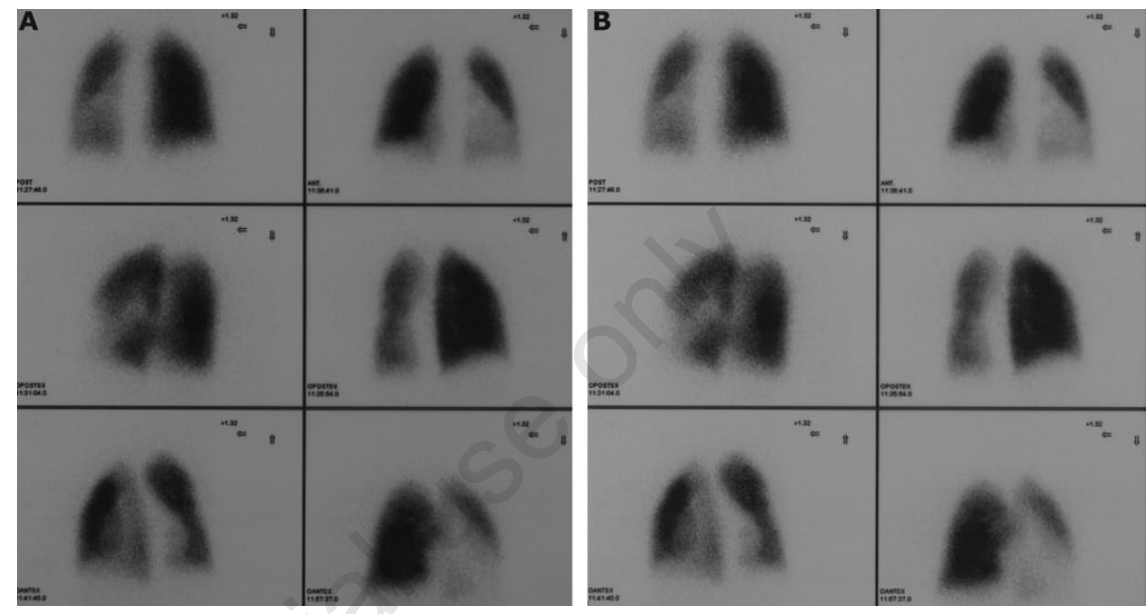

Figure 1. Pulmonary perfusion scintigraphy before (A) and 1 year after BMT (B)

thrombosis does occur in $\mathrm{PH}$, but seems to represent a primary aetiology only in a limited number of cases. ${ }^{15}$

BMT has reversed both hemolysis and $\mathrm{PH}$ in two cases of Evans Syndrome presenting with severe clinical manifestations. ${ }^{16}$ BMT has also substantially reduced cranial blood velocity ${ }^{17}$ and succeeded in stabilizing both cerebral vasculopathy and lung function in paediatric patients with SCD. ${ }^{18,19}$

The normalization of TRV in our patient after BMT, despite the persistent hypoperfusion of the left lung, might be due to the $\mathrm{HbAA}$ BMT-related elimination of hemolysis and inflammation, with a substantial increase in haemoglobin (from 8.01 to $12.3 \mathrm{~g} / \mathrm{dL}$ ), and to the improvement of vascular function. In fact, while $\mathrm{HU}$ reduces hemolysis, reduces adhesion molecules (on red cells, platelets, WBC and vascular endothelium) and seems to improve vascular tone ${ }^{14}$ while displaying controversial effects on inflammation, ${ }^{20}$ BMTespecially if a BMT with HbAA donor- eliminates hemolysis and inflammation, improves rheological characteristics and determines substantial vascular repair with restoration of the endothelial lining and maintenance of vascular homeostatis. ${ }^{21}$

Under the umbrella of Doppler-defined PH probably fall different subgroup of patients in which the various pathogenetic events (hemolysis, oxidant stress, inflammatory stress, chronic thromboembolism, in situ thrombosis, chronic hypoxemia with activation of proliferative mediators, parenchymal and vascular injury) may be differently involved and may require different therapeutic approaches. ${ }^{9,10,22}$ In very young patients, TRV elevation might express a biomarker of disease severity and systemic vasculopathy ${ }^{5}$ instead of true $\mathrm{PH}$ and only prospective trials evaluating pulmonary vascular resistance could aid in clarifying this issue.

Nevertheless, our case shows that TRV reduction in young patients, having experienced recurrent ACS with mild hemolysis and persistent TRV elevation resistant to HU treatment, can be a positive concomitant effect of BMT.

\section{References}

1. Ambrusko SJ, Gunawardena S, Sakara A, et al. Elevation of tricuspid regurgitant jet velocity, a marker for pulmonary hypertension in children with sickle cell disease. Pediatric Blood and Cancer 2006;47:90713. 
2. Gladwin MT, Sachdev V, Jison ML, et al. Pulmonary hypertension as a risk factor for death in patients with sickle cell disease. N Engl J Med 2004;350:886-95.

3. Minniti CP, Sable C, Campbell A, et al. Elevated tricuspid regurgitant jet velocity in children and adolescents with sickle cell disease: association with hemolysis and hemoglobin oxygen desaturation. Haematologica 2009;94:340-7.

4. Colombatti R, Maschietto N, Varotto E, et al. Pulmonary hypertension in sickle cell disease children under 10 years of age. $\mathrm{Br}$ J Haematol 2010;150: 601-9.

5. Morris CR. Vascular risk assessment in patients with sickle cell disease. Haematologica 2011;96:1-5.

6. Parent F, Bachir D, Inamo J, et al. A hemodynamic study of pulmonary hypertension in sickle cell disease. N Engl J Med 2011;7:44-53

7. Chaudry RA, Cikes M, Karu T, et al. Paediatric sickle cell disease: pulmonary hypertension but normal vascular resistance. Arch Dis Child 2011;96:131-6

8. Dham N, Ensing G, Minniti C, et al. Prospective echocardiography assessment of pulmonary hypertension and its potential etiologies in children with sickle cell disease. Am J Cardiol 2009;104:713-20.

9. Bunn HF, Nathan DG, Dover GJ, et al. Pulmonary hypertension and nitric oxide depletion in sickle cell disease. Blood 2010 May 14 [Epub ahead of print]

10. Hebbel RP. Reconstructing sickle cell dis- ease: A data-based analysis of the "hyperhemolysis paradigm" for pulmonary hypertension from the perspective of evidencebased medicine. Am J Hematol 2001;86: 123-54.

11. Pashankar FD, Carbonella J, Bazzy-Asaad, A, Friedman A. Longitudinal follow up of elevated pulmonary artery pressures in children with sickle cell disease. Br J Haematol 2009;144:736-41.

12. Olnes M, Chi A, Haney C, et al. Improvement in hemolysis and pulmonary arterial systolic pressure in adult patients with sickle cell disease during treatment with hydroxyurea. Am J Hematol 2009;84: 530-2.

13. Gordeuk VR, Campbell A, Rana S, et alRelationship of erythropoietin, fetal hemoglobin, and hydroxyurea treatment to tricuspid regurgitation velocity in children with sickle cell disease. Blood 2009;19: 4639-44.

14. Rees DC.The rationale for using hydroxycarbamide in the treatment of sickle cell disease. Haematologica 2011;96:488-91.

15. van Beers EJ, van Eck-Smit BL, Mac Gillavry MR, et al. Large and medium-sized pulmonary artery obstruction does not play a role of primary importance in the etiology of sickle-cell disease-associated pulmonary hypertension. Chest 2008;133:64652.

16. Connor P, Veys $\mathrm{P}$, Amrolia $\mathrm{P}$, et al. Pulmonary hypertension in children with Evans syndrome. Pediatric Hematology
Oncology 2008;25:93-8

17. Steen RG, Helton KJ, Horwitz EM, et a. Improved cerebrovascular patency following therapy in patients with sickle cell disease: initial results in 4 patients who received HLA-identical hematopoietic stem cell allografts. Annals of Neurology 2001;49:222-9

18. Bernaudin F, Socie G, Kuentz M, et al. Long-term results of related myeloablative stem-cell transplantation to cure sickle cell disease. Blood 2007;110:2749-56.

19. Walters MC, Hardy K, Edwards S, et al. Pulmonary, gonadal, and central nervous system status after bone marrow transplantation for sickle cell disease. Biol Blood Marrow Transplant 2010;16:263-72.

20. Lanaro C, Franco-Penteado CF, Albuqueque DM, et al. Altered levels of cytokines and inflammatory mediators in plasma and leukocytes of sickle cell anemia patients and effects of hydroxyurea therapy. J Leuk Biol 2009;85:235-42.

21. Sata M. Role of circulating vascular progenitors in angiogenesis, vascular healing, and pulmonary hypertension: lessons from animal models. Arteriosclerosis Thrombosis and Vascular Biology 2006;26: 1008-14.

22. Manci EA, Culberson DE, Yang YM, et al. Investigators of the Cooperative Study of Sickle Cell Disease. Causes of death in sickle cell disease: an autopsy study. Br J Haematol 2003;123:359-65. 